\title{
Ectodermal dysplasia-sensorineural deafness syndrome
}

INSERM

\section{Source}

INSERM. (1999). Orphanet: an online rare disease and orphan drug data base.

Ectodermal dysplasia-sensorineural deafness syndrome. ORPHA:1883

Ectodermal dysplasia-sensorineural deafness syndrome is characterised by hidrotic ectodermal dysplasia, sensorineural hearing loss, and contracture of the fifth fingers. It has been described in brother and sister born to consanguineous parents. The girl also presented with thoracic scoliosis. The mode of inheritance is likely to be autosomal recessive. 